\title{
Prevalence of Gastrointestinal Helminth Parasites among School Children Attending Two Community Schools in Auta Balefi, Karu, Nasarawa State
}

\author{
Maikenti, James Ishaku ${ }^{1^{*}}$, Chinonso Praise Onyeacho ${ }^{2}$ \\ and Amos Zamfara Koggie ${ }^{2}$ \\ ${ }^{1}$ Department of Zoology, Faculty of Science, Federal University of Lafia, Nasarawa State, Nigeria. \\ ${ }^{2}$ Department of Biological Sciences, Faculty of Science and Technology, \\ Bingham University, Karu, Nasarawa State, Nigeria.
}

\begin{abstract}
Authors' contributions
This work was carried out in collaboration among all authors. Author MJl designed the study, wrote the protocol and first draft of the manuscripts. Author CPO managed literature searches and statistical analysis. Author AZK managed the analysis of the study and edited the last manuscripts. All authors read and approved the final manuscript.
\end{abstract}

Article Information

DOI: 10.9734/ARRB/2020/v35i230193

Editor(s):

(1) Paola Angelini, University of Perugia, Italy.

Reviewers:

(1) Victor B. Oti, Nasarawa State University, Nigeria. (2) Khadim Diongue, Cheikh Anta Diop University, Senegal. (3) Oluboyo, Bernard Oluwapelumi, Afe Babalola University, Nigeria. Complete Peer review History: http://www.sdiarticle4.com/review-history/56018

Original Research Article

Received 05 February 2020

Accepted 10 April 2020

Published 17 April 2020

\section{ABSTRACT}

Aim: To determining the prevalence of gastrointestinal helminth parasites among school children attending two community schools in Auta-balefi, Karu. Nasarawa State.

Place and Duration of Study: The study was conducted between July and August, 2019 in two community schools in Auta-balefi, Karu Local Government Area, Nasarawa State, Nigeria.

Methodology: Microscopic examination of faecal sample from 288 pupils (143 males and 145 females) from ages 5 years and above was carried out using formol-ether concentration technique. Questionnaires were also administered and only pupils whose parents gave their consents were enrolled in the study.

Results: This study recorded an overall prevalence of $45.1 \%$ gastrointestinal helminth infection. The study however, identified the following parasites in descending order: hookworm (30.76\%), Ascaris 
lumbricoides (25.4\%), Schistosoma mansoni (17.7\%), Strongyloides stercoralis (13.8\%), Proglottids of tapeworm $(10.78 \%)$, Fasciola hepatica $(1.5 \%)$. Males $(51.0 \%)$ were more infected as well as children between the ages $11-15$ years with (48.3\%). Risk factors such as: The educational status and occupation (higher education and unskilled job) of the parents, use of water closet and use of well water and contact with soil were found to contribute to the prevalence of intestinal helminths infection in the study. This is because of the significant association of present of parasites and the prevalence of the parasites $(P>0.05)$.

Conclusion: The overall prevalence of gastrointestinal helminths parasite at the end of the study was $(45.1 \%)$ which is considered to be high compare to previous study carried on the related subject matter and also certain risk factors were considered to be the reason for such high observation. The prevalence in this study is one to be worried about considering the harm these parasites has on the health and livelihood of children who need to be healthy to carry out their everyday functions.

Keywords: Prevalence; helminths parasites; children; Auta-balefi.

\section{INTRODUCTION}

Helminths infection is a major health problem of children from rural areas of developing countries and it is an important cause of morbidity in school age children especially primary school pupils who harbor the highest intensity of worm infection [1,2].

Intestinal parasites or soil transmitted helminths are the most common Neglected Tropical Diseases (NTD) worldwide which continues to cause significant morbidity in Nigeria and in less developed tropical and subtropical countries [3]. In endemic countries, gastro-intestinal infections are most prevalent in rural communities, periurban settings and urban storm [4].

Four species are responsible for widespread disease in humans and these include Ascaris lumbricoides, Trichuris trichiura, hookworm (Ancylostoma duodenale and Necator americanus) and Strongyloides stercoralis [4].

Approximately 2 billion people are infected with helminths worldwide, which are endemic in most tropical countries; however, this may be an underestimate of the true global distribution $[5,6$, 7]. Infection and transmission are propagated by poor hygienic habits such as indiscriminate disposal of human and animal faeces, which permits contact of faeces and its accompanying egg and larvae with soil or water. Generally, helminths infections are associated with poverty, lack of sanitation, impaired hygiene and overpopulation [4]. In Nigeria, a considerable amount of human and animal wastes are discharged into the soil daily leading to the contamination of the soil with helminths eggs and larvae [8].
The public health importance of intestinal helminths infections continues due to their effects on both the nutritional and immune state of infected individuals, particularly those living in tropical and subtropical areas. Intestinal helminthic infections mainly affect the physical and mental development of children who are the most vulnerable. The prevention and control of these parasite are mainly by mass drug distribution. However, chemotherapy alone does not solve the problems and the role of others measure such as sanitation and health education should be considered. The success or failure of control measures may depends mainly on man's behavioral attitude and practices. Therefore, the participation of the community in active program directed towards the improvements of their health and standard of living is of significant importance [9].

The activities of children living in developing countries and their continuous exposure to contaminated soil and water has led to the persistent burden of soil transmitted helminths and higher prevalence ranging from $50 \%$ to $80 \%$ [10].

Gastrointestinal infection caused by Endoparasites is endemic in most developing countries. It affect people of all ages and gender. Infection with these parasites have been associated with high morbidity which affects Nutritional status especially in school age children, leading to malnutrition, growth retardation, anemia and sometimes poor mental development of the infected individual. The state of personal and environmental hygiene in Nigeria is generally poor, People and animals often defaecate in the open daily introducing faecal matter and its accompanying parasitic contents (among others) to the soil. This poor hygienic 
habit and indiscriminate disposal of human animals waste and their accompanying parasite egg and larvae into the soil or water serves as a sources of infection. With approximately 2 billion people infected with helminths parasites worldwide, the parasites will still remain the most neglected Tropical Disease worldwide [11].

Gastrointestinal helminths are on the increase in sub-Saharan countries such as Nigeria. Several environmental and socioeconomic factors have been pointed as determinate for the continuous persistence of intestinal helminths. Some of which includes unhygienic personal practices, lack of potable water and poor housing facilities. In view of the negative socioeconomics impacts of these parasites in the study area, there is a need for development of good preventive and control measures. For this to be achieved there is need for the generation of data on the prevalence of gastrointestinal helminths in the study area.

This project was designed to help record the endo-parasitic profile in the gastrointestinal tract of School children and give awareness about the parasites and its impacts on health and furthermore, suggest proper treatment, control and preventative measures to children.

This study was aimed to determine the prevalence of gastrointestinal helminth parasites among school children attending two community schools in Auta-balefi Karu, Nasarawa State. Specific objectives was to associate the infection with the risk factors of gastrointestinal helminths in the study area.

This study will educate the school children of the respective schools on Gastrointestinal Helminths Parasites: its causes, symptoms, treatments and its prevention and control. It will also provide the health workers on the prevalence status of helminthic parasite.

\section{MATERIALS AND METHODS}

\subsection{Study Area}

The study was conducted in two community schools in Auta-balefi which is a village in north central Nigeria. It is located in Karu local government area (LGA) along Abuja- keffi Road, Nasarawa State. Area $2640 \mathrm{~km}^{2}$ Latitudes $8^{\circ} 5^{\prime} \mathrm{N}$ and $10^{\circ} 42^{\prime} \mathrm{N}$ and longitudes $9^{\circ} 25^{\prime} \mathrm{E}$ and $7^{\circ} 54^{\prime} \mathrm{E}$ of the Greenwich Meridian. It is close in proximity to the Federal Capital Territory of Nigeria [12].

\subsection{Study Design}

This study was randomized to determine the prevalence of gastrointestinal helminth parasite in the study area. The study was carried out in two randomly selected in Auta-balefi namely; Government Secondary School Kodape and LGEA Kodape. A well designed questionnaire was used to obtain information from two hundred and eighty eight (288) students.

\subsection{Sample Size}

A total of 288 stool samples was collected from School children during the period of the study. The sample size was determined using the following equation:

$N=\frac{Z^{2} \times P(1-P)}{D^{2}}$

Where,

$Z=$ Statistics for level of $95 \%$ confidence

$\mathrm{P}=$ prevalence rate of previous studies $=0.25$

[13]

$\mathrm{D}=5 \%$ precision $=0.05$

$\mathrm{N}=$ Sample size

$\frac{1.96^{2} \times 0.25(1-0.25)}{0.05^{2}}$

$\underline{3.84 \times 0.25(0.75)}$

0.0025

$\frac{0.72}{0.0025}$

$=288$.

Hence, the minimum sample size required for this study was 288 .

\subsection{Collection of Faecal Specimens}

Stool samples were collected from all the participants in each school between 10.00 am and $1.00 \mathrm{pm}$ when most of the children were in attendance in the schools. All participating children were supplied with a clean labeled plastic universal bottle with screw cap with a plastic spatula each. Prior to collection, pupils were instructed on how to collect the samples, as described by Egwuari [14]. 


\subsection{Examination of Faecal Specimens}

\subsubsection{Formal ether concentration}

$1 \mathrm{~g}$ of faeces was emulsified in about $4 \mathrm{ml}$ of $10 \%$ formol water contained in a screw-cap bottle tube. Further, further 3-4 $\mathrm{ml}$ of $10 \%$ formol water was added; the tube was capped and was mixed by shaking for about 20 seconds. The emulsified faeces was sieved into a suspension beaker and the suspension was transferred in to centrifuge tube made of polypropylene, equal volume of ether $(4 \mathrm{ml})$ was added to the tube, capped and mixed for 1 minute. After mixing a tissue was wrapped around the tube to loosen the stopper. The tube was spun immediately at $3000 \mathrm{rpm}$ (revolution per minute) for 1 minute. After centrifuging, the parasite sediment to the bottom of the tube and the faecal debris formed a layer between the ether and formol water. A plastic bulb pipette was used to loosen the layer of faecal debris from the side of the tube and was rapidly inverted to discard the ether, faecal debris and formol water. The tube was returned in an upright position and the fluid on the side was allowed to drain back to the bottom of the tube a bulb pipette was used to mix the sediment and the sediment was transferred to the glass slide and 1 drop of normal saline was added and covered with a cover slip. The sediment was examined microscopically using $\times 10$ and $\times 40$ respectively [15].

\subsection{Identification of Helminths}

Diagnosis depended principally on the identification of eggs or larvae of parasites in feaces.

\subsection{Estimation of Prevalence}

Prevalence rate of infested pupils was calculated using the formula:

$$
\begin{aligned}
& \text { Prevalence }(\%)= \\
& \frac{\text { Number of Pupils tested positive }}{\text { Number of Pupils Tested }} \times 100
\end{aligned}
$$

\subsection{Data Was Analysis}

Data generated from the research was analyzed using Statistical Package for Social Sciences (SPSS, IBM version 21). Chi-square test was used to compare mean prevalence.

Statistical significance was measured at $p<$ 0.05 .

\section{RESULTS}

\subsection{Characteristic of the Study Population}

This study examined a total of 288 pupils attending two community schools in the kodape, Auta Balefi, Karu. The pupils whose age ranges between 5 and 25, were 143 males and 145 females. The major occupation of the parents include farming (74), civil servants (93), traders (64) and others (57). Educational status of the parents also reveals that 8 are illiterates, 13 with primary school leavers, 168 secondary school and 99 tertiary education.

\subsection{Prevalence of Gastrointestinal Parasites in Two Community Schools in Auta Balefi}

The overall prevalence of gastrointestinal helminths parasite among school children in the study area is $45.1 \%$ with the occurrence of Six intestinal parasites isolated, which includes Ascaris lumbricoides (25.39\%), Strongyloides stercoralis (13.85\%), Hookworm (30.79\%), Schistosoma mansoni (17.69\%), proglottids of tapeworm $(10.77 \%)$ and Fasciola hepatica $(1.54 \%)$ (Table 1).

\subsection{Occurrence of Gastrointestinal Helminth Parasites in School Children}

Six intestinal parasites were isolated from school children in this study. These parasites includes Ascaris lumbricoides (25.4\%), Strongyloides stercoralis (13.8\%), Hookworm (30.8\%), Schistosoma mansoni (17.7\%), Proglottids of tapeworm (10.8\%) and Fasciola hepatica (1.5\%) (Table 1).

\subsection{Prevalence of Gastrointestinal Helminths in Relation of Age}

Out of the total number of school children examined, $4(22.2 \%)$ of them between the age ranges of 5-10 were positive for gastrointestinal helminths, $72(48.3 \%)$ of those within the age group of 11-15 were positive, 51 (45.1\%) of those within the age group of 16-20 were positive for helminths parasites while $3(37.5 \%)$ those above 20 years of age were positive for helminths infection. There was no significant difference in helminths infection between the ages $(p>0.05)$ (Table 2$)$. 


\subsection{Prevalence of Gastrointestinal Helminths in Relation to Sex}

Majority of the Children examined were females (145). Nevertheless, males had a higher prevalence of gastrointestinal helminths $(51.0 \%)$ than females $(39.3 \%)$ the difference was statistically significant $(\mathrm{P}<0.05)$ (Table 3$)$.

\subsection{Prevalence of Gastrointestinal Helminths in Relation to Educational Status of Parents}

Prevalence of gastrointestinal helminths was highest among school children whose parents had highest educational qualification from a tertiary institution (49.5\%). Those whose parents had primary school education had prevalence of $46.2 \%$, secondary school had prevalence of $44.0 \%$ while those with primary school and no education had prevalence of $44.0 \%$ and $12.5 \%$ respectively. There was also no significant difference between rates of infection and educational qualification of parents as $P>0.05$. (Table 4).

\subsection{Prevalence of Gastrointestinal Helminth in Relation to Parent's Occupation}

In terms of occupation, $37(50.0 \%)$ of the 74 school children whose parents were farmers were positive for helminths infection while $44.1 \%$, $32.8 \%$ and $54.4 \%$ of the school children whose parents were civil servants, traders, and belonged to other occupation were positive for helminths infection respectively.

\subsection{Prevalence of Gastrointestinal Helminths in Relation to Source of Water}

In terms of source of water, 4 of the children who consume well water $(66.7 \%)$ were positive for helminths infection, $40.8 \%$ of the children who consume borehole water were positive, $30.4 \%$ of those who consume sachet water were positive while $38.1 \%$ of those who consume bottled water were positive for helminths infection (Table 5).

\subsection{Prevalence of Gastrointestinal Helminths in Relation to Deworming}

For deworming, the school children who have been dewormed in the past had a lower prevalence of infection $(44.7 \%)$ than those who were not $(45.7 \%)$. Those who deworm monthly also recorded higher prevalence rates than those who deworm yearly (41.9\%). There was however no significant difference in the rates of deworming $(P>0.05)$.

The risk factors such as; The Educational status and occupation (higher education and unskilled job) of the parents, use of water closet and use of well water, and contact with soil were found to contribute to the prevalence of intestinal parasitic infection, although, showed statistical significant association with the presence of parasites in their stool samples $(P>0.05)$.

\section{DISCUSSION}

Nasarawa State is one of the state where there is an ongoing intervention through a periodic

Table 1. Prevalence of gastrointestinal helminth parasites in school children attending two community schools in Auta Balefi, Karu

\begin{tabular}{lll}
\hline Number examined & Number positive (\%) & Prevalence \\
\hline 288 & 130 & $45.1 \%$ \\
\hline
\end{tabular}

Table 2. Occurrence of gastrointestinal helminths parasites in school children

\begin{tabular}{lll}
\hline Gastrointestinal helminth & Frequency & Prevalence \\
\hline Ascaris lumbricoides & 33 & 25.4 \\
Srongyloides stercolaris & 18 & 13.8 \\
Hook worm & 40 & 30.8 \\
Schistosoma mansoni & 23 & 17.7 \\
Tape worm proglottid & 14 & 10.8 \\
Fasciola sp. & 2 & 1.5 \\
\hline Total & 130 & 100 \\
\hline
\end{tabular}


Table 3. Prevalence of gastrointestinal helminths in relation to age and gender

\begin{tabular}{lllll}
\hline Age group & Number examined & Number infected & Prevalence & P-value \\
\hline $5-10$ & 18 & 4 & 22.2 & 0.20 \\
$11-15$ & 149 & 72 & 48.3 & \\
$16-20$ & 113 & 51 & 45.1 & \\
Above 20 & 8 & 3 & 37.5 & \\
Total & & & 45.1 & \\
\hline Gender & & 73 & 51.0 & 0.04 \\
\hline Male & 143 & 57 & 39.3 & \\
Female & 145 & & 45.1 & \\
\hline Total & & &
\end{tabular}

Table 4. Prevalence of gastrointestinal helminths in relation to parent's educational status and occupation

\begin{tabular}{lllll}
\hline Factor & $\begin{array}{l}\text { Numbers } \\
\text { examined }\end{array}$ & $\begin{array}{l}\text { Number } \\
\text { infected }\end{array}$ & Prevalence & P-value \\
\hline Educational level of parents & & & & \\
\hline None & 8 & 1 & 12.5 & 0.23 \\
Primary & 13 & 6 & 46.2 & \\
Secondary & 168 & 74 & 44.0 & \\
Tertiary & 99 & 49 & 49.5 & \\
\hline Total & & & 45.1 & \\
\hline Occupation of parents & & & & \\
\hline Famers & 74 & 37 & 40.0 & 0.08 \\
Civil servants & 93 & 41 & 32.8 & \\
Traders & 64 & 21 & 54.4 & \\
Others & 57 & 31 & & \\
\hline
\end{tabular}

Table 5. Prevalence of gastrointestinal helminths in relation to predisposing factors

\begin{tabular}{lllll}
\hline Predisposing Factors & No. examined & No. infected & Prevalence & P-value \\
\hline Sources of water & & & & \\
\hline Well water & 6 & 4 & 66.7 & 0.09 \\
Borehole & 215 & 104 & 40.8 & \\
Sachet water & 46 & 14 & 30.4 & \\
Bottle water & 21 & 8 & 38.1 & \\
\hline Total & 288 & 130 & 45.1 & \\
\hline Deworming & & & & \\
\hline Yes & 150 & 67 & 44.7 & 0.87 \\
No & 138 & 63 & 45.7 & 0.83 \\
\hline Frequency of deworming & & & & \\
\hline Monthly & 106 & 47 & 44.7 & 8.83 \\
Yearly & 44 & 18 & & \\
\hline Walking bare foot & & & & 64.4 \\
\hline Walking bare foot & 45 & 29 & & 41.6 \\
No & 243 & 101 & 45.1 \\
Total & & & \\
\hline
\end{tabular}

deworming of pupils in schools. However, this study revealed a high prevalence of $45.5 \%$ among the study population. This prevalence rate is higher than an overall prevalence of 28.9\% reported by Ekpenyong [18]. But lower than a prevalence rate of $52.5 \%$ reported by
Ogalue [20]. Constancy [17] who reported a prevalence rate of $88.0 \%$ and that of [16] who reported a prevalence of $48.7 \%$.

The high prevalence recorded in this this study could be as a result continues exposure to 
sources of infection as result of poor personal hygiene practice and environmental sanitation.

The study recorded the existence of six gastrointestinal helminths. This included Ascaris lumbricoides, Strongyloides stercoralis, Hookworm, Schistosoma mansoni, Tapeworm and Fasciola hepatica. Highest occurrence of gastrointestinal helminths infection was Hookworm infection while least prevalence of infection was for Fasciola hepatica.

The occurrence of these gastrointestinal parasites is similar to the report of Udensi [16] who reported the same helminths in their study on prevalence of intestinal parasites among primary school children in three geopolitical zones of Imo state in Nigeria. It is also similar to the reports of Constancy [17] and Ekpenyong [18] who reported the occurrence of similar parasites among school children in Calabar South Local Government of Cross River States and Igbo-Eze South Local Government Area of Enugu State, both in Nigeria. The findings of this study however differs from the findings of Eniola [10] in that Ascaris lumbricoides recorded highest prevalence in contrast to Hookworm which was characteristic of this study. High occurrence of hookworm in this study might be as a result of continuous exposure to sources of infection as a result of poor hygiene practices and poor sanitation.
In terms of age group, the age group of $11-15$ years recorded the highest rate of infections with gastrointestinal helminths. Highest prevalence within this age group differs markedly from the report of Ekpenyong [18] who reported that children within the age group of 4-6 recorded highest prevalence of gastrointestinal helminths. Highest prevalence in age group 11-15 years is however similar to the report of Ogalue [20] who reported highest prevalence of gastrointestinal parasites among age group 10-13 years. The age group recorded for this study might be the age where the pupil are most active playing outside the environments which predisposes them to having contact with soil.

Infection rate of gastrointestinal helminths infection varied between sexes with males recording a higher prevalence of infection $(51.0 \%)$ than females (39.3\%). Statistical analysis also showed that there was a significant difference between infection according to the sex $(p=0.04)$. Highest prevalence of infection recorded among males may be attributed in part to the super active nature of males who mostly engage themselves in activities such as playing in the soil that exposes them to ova of helminthes such as hookworm which was most abundant in this study. Females on the other hand are quite reserved and as such recorded lower prevalence when compared to males.

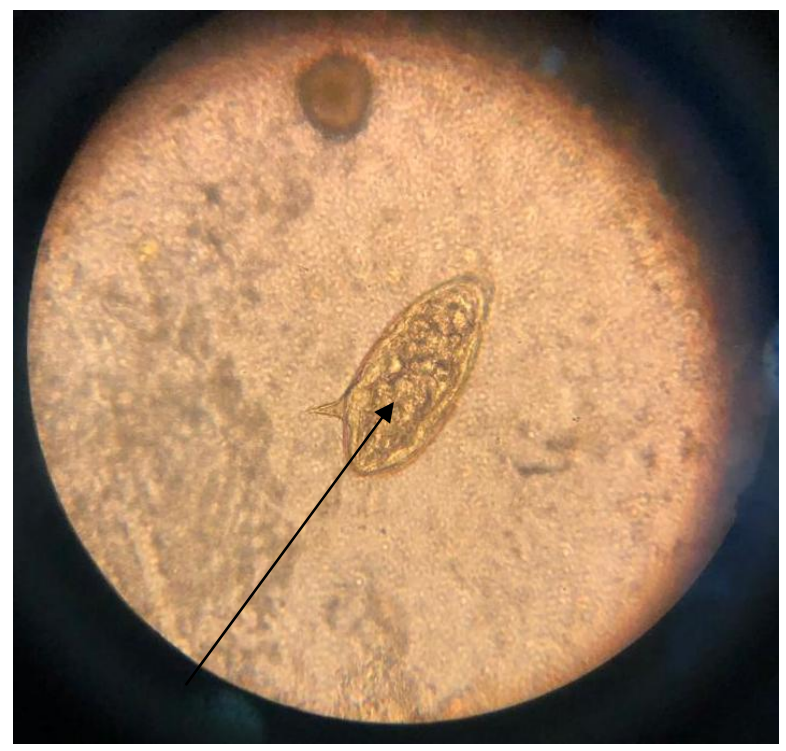

Plate 1. Egg form of Schistosoma mansoni 


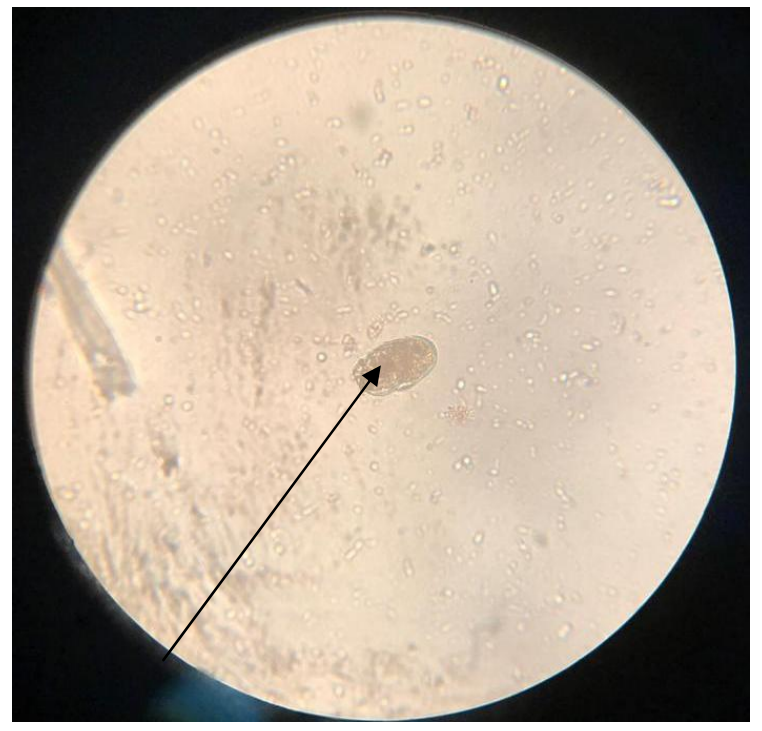

Plate 2. Ova of hookworm

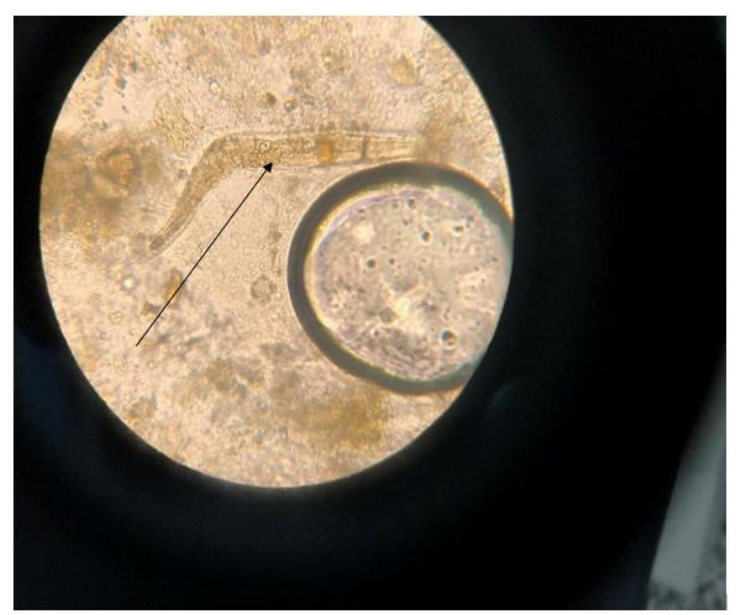

Plate 3. Larva of Strongyloides stercoralis

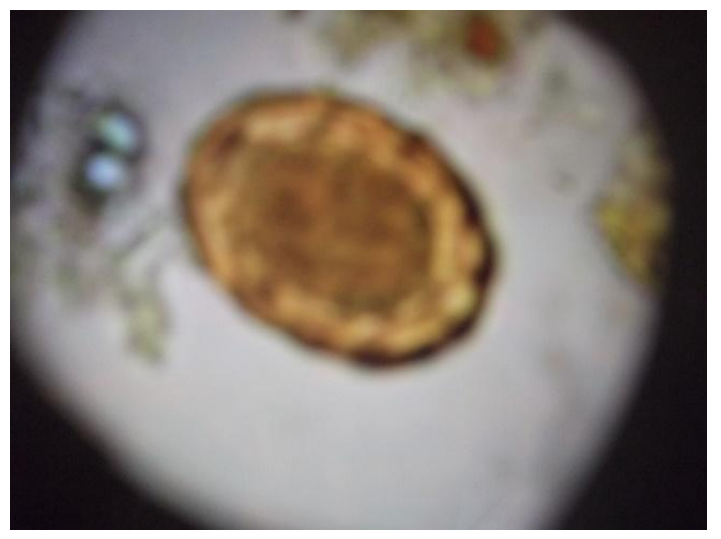

Plate 4. Ova of Ascaris lumbricoides 
Highest prevalence of infections as observed in this study is in disagreement with the findings of Ogalue [20] and Ekpenyong [18] who reported higher prevalence of infection in females. The findings of this study are however in agreement with the findings of Constancy [17] who reported that males have a higher prevalence of infection than females.

In terms of occupation of parents of the school children, those whose parents were farmers had highest prevalence of infection $(50.0 \%)$ when compared to other specific types of occupation. This high prevalence of infection among this category of school children might be attributed to the ease with which the children encounter geohelminths in the soil during the course of helping their parents on their farms; a possible reason for lower prevalence recorded by children whose parents belong to other classes of occupation. Similar report has been presented by Ogalue [20] who recorded highest prevalence of infections among children whose parents were farmers. The findings of this study however differed from that of Ogalue [20] in that there was no significant relationship between occupation and prevalence of gastrointestinal helminths $(p>0.05)$.

Water sources affected the prevalence of gastrointestinal helminths in this study with those who consume well water having highest prevalence of infection (66.7\%) followed by those who consume borehole water $(40.8 \%)$ while least prevalence was recorded for by those who consume sachet water. Well water sources are potent sources of infection since the water sources are usually exposed most of the times and this can lead to contamination by helminthes which most times require water sources for their propagation. Also, walking barefooted was statistically significant $(p<0.05)$ with those who walk barefooted recording the highest prevalence of infection $(64.4 \%)$ when compared to those who do not.

Deworming seemed to affect the outcome of infection prevalence in this study since those who have been dewormed in the past recorded least prevalence than those who have not. Statistical analysis however showed that this association was not significant $(p>0.05)$. A nonsignificant association in this study however differs from the findings of Ogalue [20] who reported a strong association between deworming and intestinal infection $(P<0.05)$.

\section{CONCLUSION}

The overall prevalence of gastrointestinal helminths parasite at the end of the study was (45.1\%) which is considered to be high compare to previous study carried on the related subject matter and also certain risk factors were considered to be the reason for such high observation. The prevalence in this study is one to be worried about considering the harm these parasites has on the health and livelihood of children who need to be healthy to carry out their everyday functions.

\section{RECOMMENDATIONS}

- Preventive measures and surveillance systems should be emphasized by the government through various means.

- In view of morbidity and medical complications of gastrointestinal helminths, free medical tests and periodic deworming of school children in Nasarawa should be carried out and sustained so as to help eradicate most of the parasitic infections present in Nasarawa State.

- The public should be enlightened on the occurrence, mode of infection and the health impacts of gastrointestinal parasites. This enlightenment should be done at various levels ranging from schools to the civil service. This calls for a synergy between the ministries of Education, health and works.

- Environment sanitation and personal hygiene programs should be introduced to schools and communities and sanitation laws should be enacted and enforced on all citizens to curb the transmission and spread of gastrointestinal parasites.

\section{CONSENT}

Authors declare that written consent form was given to parents/guardian of the pupils and only those whose parents/guardian gave their consent were sampled for the study.

\section{ETHICAL APPROVAL}

Ethical approval to conduct research was sought from Nasarawa State Hospital Management Broad (NSHMB) through the Research Ethics Committee of Nasarawa State ministry of Health Lafia, in line with the guidelines required for conducting research on human samples (NO:NHREC 18/06/2017). 


\section{ACKNOWLEDGEMENTS}

The lead author wish to acknowledge Parent teachers Association of the selected community for giving their consent for the research. The staff of those school also assisted during sample collection, thank you all.

\section{COMPETING INTERESTS}

Authors have declared that no competing interests exist.

\section{REFERENCES}

1. Opaleye OO, Bolaji OS, Ojurongbe TA. Soil transmitted helminth infection. Nigerian Journal of Parasitology. 2014;34 (1):15-30.

2. Adeyeba OA, Akinlabi AMJ. Intestinal parasitic infection among school children in a rural community, South-West Nigeria. Nigerian Journal of Parasitology. 2002;23 (1):11-18.

3. WHO. A roadmap for implementation: Accelerating work to overcome the global impact of neglected tropical diseases; World Health Organization: Geneva, Switzerland; 2012.

Available:http://www.who.int/neglected_dis eases/NTD_RoadMap_2012_Fullversion.p dfhttp://apps.who.int/ris/bitstream/10665/7 0809/1/WHO_HTM_NTD_2012.1_eng.pdf

4. Brooker S, Clement AC, Bundy DA. Global epidemiology, ecology and control of soil- transmitted helminth infections. Advance in Parasitology. 2006;62:221261.

5. Williams L. Public health significance of intestinal parasite infection. Bull World Health Organization. 2005;65(5):573585.

6. Albonico M, Crompton DW, Savioli L. Control strategies for human intestinal helminth nematode infection. Advanced Parasitology. 1999;42:277-341.

7. Zani LC, Favre TC, Pieri OS. Impact of anthelmintic treatment on infection by Ascaris lumbricoides. 2004;46(2):6371.

8. Ariyo F, Fagbenro-Beyioka AF, Faweya T. Helminthic reduction with albendazole among school children in riverine communities of Nigeria. Journal Rural Tropical Public Health. 2007;6:6-10.
9. WHO. Weekly Epidemiological Record, No Geneva: WHO. 2006;31(81):297308.

10. Eniola MA, Onyinye CE, Akwashiki O, Linus A, Peter OA, Akinola S. Oluwole. Helminthiasis among school-age children and hygiene conditions of selected schools in Lafia, Nasarawa State. Nigeria Tropical Medicine and Infectious Diseases. 2019;4, 112.

DOI: 10.3390/tropicalmed4030112 Available:www.mdpi.com/journal/tropicalm ed

11. Suleiman MM. Neglected tropical disease in Nigeria: Situation analysis. Advances in Social science Research Journal. 2016;3: 10.

12. BBC. Life of poverty in Abuja wealth. BBC News; 2007.

13. Taiwo OT, Sam-Wobo SO, Taiwo AM. Spatial distribution of helminths infections in Nigeria (2005-2018) and the need for attitudinal and behavioural changes in the water and sanitation and hygiene interventions. Ife Journal of Science. 2016;18:4.

14. Salawu SA, Ughele VA. Prevalence of soiltransmitted helminths among school-age children in Ife east local government area, Osun State, Nigeria. FUTA Journal of Science. 2015;(1)139-151.

15. Cheesebrough $M$. District laboratory practice in tropical countries. Parts I. Edinburgh, Cambridge University Press. 1998;196-198.

16. Udensi JO, Mgbemena IC, EmakaNwabunnia I, Ugochukwu MG, Awurum IN. Prevalence of intestinal parasites among primary school children in Three Geopolitical Zones of Imo State, Nigeria. Science Journal of Public Health. 2015;3 (5-1):25-28.

17. Constancy A, Sam A, Uchechukwu O, Ibioku E, Serekara C, Miriam H. The prevalence of intestinal helminth infections among Primary School Children in Calabar South Local Government Area, Cross Rivers State, Nigeria. International Journal of Science and Research. 2013;5(2): 1809-1814.

18. Ekpenyong EK, Eyo JE. Prevalence of intestinal helminth among schooling children in Tropical Semi Urban Communities. Animal Research; 2008. 
19. Tsega $T$, Shewaye $B$, Desalegn $T$, Abraham A, Gimay T. Prevalence of intestinal helminth and associated factors among school children of Medebay Zana Wereda; North Western Tigay, Ethiopia. BMC Research Notes. 2018;11(444): 1-6.
20. Ogalue UM, Ekejindu IM, Ochiabuto OM, Obi MC, Obeagu E, Ekelozie IS. Intestinal parasites, Malaria and Anaemia among school children in some flood affected areas of Ogbaru Local Government Area of Anambra State, Nigeria. Archives of Clinical Microbiology. 2018;9(2):1-6.

(c) 2020 Ishaku et al.; This is an Open Access article distributed under the terms of the Creative Commons Attribution License (http://creativecommons.org/licenses/by/4.0), which permits unrestricted use, distribution, and reproduction in any medium, provided the original work is properly cited.

Peer-review history:

The peer review history for this paper can be accessed here: http://www. sdiarticle4.com/review-history/56018 